\title{
The effects of perceptual load in processing emotional facial expression in psychotic disorders
}

\author{
Joana Grave $^{\mathrm{a}}$, Sandra C. Soares ${ }^{\mathrm{a}, \mathrm{b}, \mathrm{c}}$, Sofia Morais ${ }^{\mathrm{d}, \mathrm{e}}$, Paulo Rodrigues ${ }^{\mathrm{f}}$, Nuno Madeira ${ }^{\mathrm{d}, \mathrm{e}, *}$ \\ a Department of Education and Psychology, University of Aveiro, Aveiro, Portugal \\ b Center for Health Technology and Services Research (CINTESIS-UA), Department of Education and Psychology, University of Aveiro, Aveiro, Portugal \\ ${ }^{\mathrm{c}}$ Department of Clinical Neurosciences, Division of Psychology, Karolinska Institute, Stockholm, Sweden \\ d Psychiatry Department, Coimbra Hospital and University Centre, Coimbra, Portugal \\ e Department of Psychological Medicine, Faculty of Medicine, University of Coimbra, Coimbra, Portugal \\ ${ }^{\mathrm{f}}$ Department of Psychology and Education, University of Beira Interior, Covilhã, Portugal
}

\section{A R T I C L E I N F O}

\section{Keywords:}

Psychotic disorders

Schizophrenia

Attentional control

Emotional facial expressions

Perceptual load

Social cognition

\begin{abstract}
A B S T R A C T
Psychotic disorders are some of the most severe psychiatric conditions. Patients have difficulties in identifying facial expressions and appear to be highly sensitive to the presence of emotional distractors. Yet, no study has investigated whether perceptual load modulates the interference of emotional distractors. Our goal was to test whether psychotic patients were more sensitive to irrelevant emotional stimulus, even when the task demands a high amount of attentional resources. Twenty-two participants with schizophrenia or schizoaffective disorder and twenty-two healthy controls, performed a target letter discrimination task with emotional task-irrelevant stimulus (angry, happy and neutral facial expressions). Target-letters were presented among distrator-letters, which could be similar (low perceptual load) or different (high load); participants should discriminate the target-letter and ignore the facial expression. Results showed that patients were more prone to distraction by task-irrelevant stimulus, especially under high load, suggesting difficulties in attention control. Moreover, in psychotic patients, happy faces caused higher interference with the task, whereas neutral and angry faces resulted in less interference. These findings could provide innovative approaches regarding attentional deficits on social contexts in patients with schizophrenia spectrum disorders.
\end{abstract}

\section{Introduction}

Psychotic disorders are one of the most severe psychiatric conditions (Perälä, 2013) and include several diagnoses such as schizotypal personality, delusional disorder, brief psychotic disorder, schizophreniform disorder, schizophrenia, schizoaffective disorder and schizophrenia spectrum and other psychotic disorders (APA, 2013). Psychotic disorders are often associated with deficits in social cognition (e.g., Penn et al., 2008), particularly in the ability to recognize others' emotional facial expressions (e.g., Addington and Addington, 1998; Kohler et al., 2000, 2010; Losiak and Siedlecka, 2013). Deficits in social cognition are strongly associated with poor functioning in psychotic patients (e.g., Couture et al., 2006; Madeira et al. 2016). Together with neurocognitive impairments, they start early in the disease course and remain largely unaffected by pharmacological treatment (e.g., Green et al., 2012; Kurtz et al., 2015; Penn et al., 2008).

From a conceptual point of view, and considering the organizational models of neural systems in social neurosciences, four general social cognitive processes have been proposed: experience sharing, mentalizing, experiencing and emotion regulation, and the perception of social cues (Green et al., 2015; Madeira et al., 2016). Research has shown that psychotic individuals have an intact affective sharing, one of the dimensions of experience sharing, although results regarding the other dimension - motor resonance, have provided mixed results (Madeira et al., 2016). In addition, they also have difficulties in mentalizing, i.e., in inferring the mental states of others (see Bora et al., 2009a; Savla et al., 2013). Regarding experience and emotion regulation, which have received a great deal of attention in the literature (Green et al., 2015), research has shown that emotion experience is largely intact during exposure to pleasant stimuli as well as in response to unpleasant stimuli, although for the latter the experience can sometimes be heightened; for emotion regulation, evidence suggests that the use of cognitive-reappraisal strategies is disrupted in this disorder (Madeira et al. 2016).

\footnotetext{
* Corresponding author at: Department of Psychological Medicine, Faculty of Medicine, University of Coimbra, Rua Larga, 3004-504 Coimbra, Portugal

E-mail addresses: joanagrave@ua.pt (J. Grave), sandra.soares@ua.pt (S.C. Soares), sofiamorais86@gmail.com (S. Morais), pjfsfr@ubi.pt (P. Rodrigues), nunogmadeira@gmail.com,nmadeira@uc.pt (N. Madeira).
} 
Finally, and most relevant to the present study, studies on the perception of social cues in psychotic disorders, which have mainly focused on facial affect processing, have showed overall facial identification deficits. More specifically, neuroimaging studies have reported a reduced involvement of facial affect regions and a concomitant over activation within the visual processing regions (see Delvecchio et al., 2013). Accordingly, behavioural studies have described impairments in the recognition of happy facial expressions (e.g., Laroi et al., 2010; Tsoi et al., 2008), although the most consistent findings involve the identification of negative emotions (e.g., Bediou et al., 2005; Namiki et al., 2007), mainly angry (e.g., Leppänen et al., 2006) and fearful expressions (e.g., Morris et al., 2009). Indeed, emotional deficits have long been recognized as cardinal symptoms of psychotic disorders, with Bleuler (1950) considering them a fundamental feature of psychotic disorders.

Attentional deficits in psychotic disorders have also been widely studied and have been demonstrated in visual search (e.g., Fuller et al., 2006; Gold et al., 2007; Lin et al., 2013; Mori et al., 1996; Tanaka et al., 2007), in negative priming (Fuller et al., 2000; Ungar et al., 2010) and in Stroop tasks (see Henik and Salo, 2004). Moreover, patients seem more susceptible to the interference of task-irrelevant stimuli than healthy controls, especially under more demanding tasks, suggesting deficits in attentional control (e.g., Demeter et al., 2013; Fuller et al., 2006; Luck and Gold, 2008; Mitchell and Rossell, 2014). One way to manipulate the task demands is through perceptual load. According to the Perceptual Load Theory (Lavie, 1995, 2005), task-irrelevant stimuli are not processed when the task requires all attentional resources (i.e., high perceptual load). Contrarily, at low perceptual load, the remaining attentional resources are involuntarily directed to task-irrelevant stimuli, allowing its processing. Ducato et al. (2008) have studied the perceptual load effects in schizophrenia using nonemotional stimuli and showed that, compared to controls, patients were more effective at inhibiting interference by task-irrelevant stimuli in the high and medium load, compared to the low load conditions. According to the authors, these effects were not the result of a heightened ability to selectively filter irrelevant information, but instead the result of limited available resources, i.e., a consequence of the higher demands of the task (Ducato et al., 2008; Granholm et al.,1997). Other studies with participants without mental disorders have, however, showed that emotional task-irrelevant stimuli, such as human faces, interfere in the task regardless of its perceptual load (e.g., Lavie et al., 2003; Öhman et al., 2012). Given their evolutionary relevance, these stimuli are processed preferentially, in particular when posing a threat (e.g., angry faces, snakes) (see Öhman, 2009, Öhman et al., 2012). Such outcome, known as the threat-superiority-effect, allows a faster and more effective detection of threatening rather than non-threatening information (e.g., happy faces, flowers, mushrooms) (Hansen and Hansen, 1988; Öhman et al., 2001a, 2001b). Importantly, studies with psychotic patients show deficits in the threat-superiorityeffect towards social stimuli (e.g., Leppänen et al., 2006; Namiki et al., 2007), but not towards non-social information (Pinkham et al., 2014). It is therefore possible that psychotic patients are more sensitive to the interference of irrelevant stimuli with emotional content at high perceptual load conditions, compared to low perceptual load, even with their limited processing resources (Ducato et al., 2008).

Accordingly, it has been proposed that psychotic patients are particularly sensitive to the presence of emotional stimuli (see Mitchell and Rossell, 2014). Surprisingly, and despite its relevance, few attentional studies on psychotic disorders have used these stimuli. Strauss et al. $(2008,2011)$ concluded that psychotic patients with deficit syndrome, i.e., particularly poor outcome and predominately entailing primary and persistent negative symptoms in schizophrenia (see Madeira et al., 2016), have greater difficulty disengaging attention from non-social unpleasant stimuli (disagreeable words), compared to neutral ones. However, Park et al. (2011) showed a steeper decline of psychotic patients' performance over time when the task-relevant stimuli were displayed with a happy face (compared to sad and neutral ones). Later, Park et al. (2012) concluded that patients' performance was significantly weaker in the presence of emotional distractors (i.e., happy faces) than ecologically less significant stimuli (non-facial distractors) (Park et al., 2012).

To our knowledge, the present study is the first empirical research on the interference of emotional stimuli in psychotic disorders as a function of perceptual load. Our purpose was to explore whether psychotic patients are more prone to processing emotional taskirrelevant stimuli, compared to healthy individuals, even in tasks that demand a higher amount of attentional resources (e.g., Foster and Lavie, 2008). We predicted that psychotic patients, compared to than healthy individuals: a) would show a higher interference by emotional stimuli, compared to control group, reflected in longer Response Times (RT) and lower accuracies; b) would be more prone to processing such stimuli at high perceptual load conditions, compared to low perceptual load conditions; c) this bias would be enhanced by negative faces (anger), compared to positive (happy) and neutral ones. This pattern of results would provide evidence for attentional impairments in social cues in psychotic disorders, contributing more broadly to understand the maladaptive behaviour of psychotic patients in social context.

\section{Methods}

The study was approved by the local Ethics Committee. Guidelines of the Declaration of Helsinki and standards of American Psychological Association were followed. All participants provided written informed consent and did not receive any reward for their participation.

\subsection{Participants}

A total of 44 participants, including 22 patients meeting DSM-5 (APA, 2013) criteria for schizophrenia $(n=21)$ or schizoaffective disorder $(n=1)$, and 22 healthy age- and gender-matched controls, participated in the present study between April and September 2014. Patients were recruited from two outpatient clinics at Coimbra Hospital and University Centre (Coimbra, Portugal) and Baixo Vouga Hospital Centre (Aveiro, Portugal), whereas healthy controls were recruited from the local community and nearby university population (Aveiro, Portugal) through advertisements in social media.

The inclusion/exclusion criteria for patients were: (1) diagnosis of schizophrenia or schizoaffective disorder meeting DSM-5 criteria (APA, 2013) based on information from medical records; (2) between 18 and 65 years of age; (3) good understanding of Portuguese language; (4) normal or corrected-to-normal visual acuity and absence of dyschromatopsia; (4) having stable psychiatric symptoms and antipsychotic medication for at least six months based on the medical record; (5) no history of substance dependence or abuse during the past six months; (6) no history of head injury and neurological diseases (Table 1).

The 22 age- and gender-matched healthy controls had to be able to understand and communicate in Portuguese and meet the following inclusion/exclusion criteria: (1) no past or present psychiatric disorder as determined by the Portuguese version of the Mini International Neuropsychiatric Interview (MINI 5.0.0; Portuguese version: Amorim, 2000); (2) no history of substance abuse, head injury, neurological disorders, other Axis I psychiatric disorders, or significantly impaired vision; (3) no history of psychotic disorders in first-degree biological relatives.

\subsection{Clinical measures}

A sociodemographic questionnaire and the Portuguese version of the Zung Self-Rating Anxiety Scale (ZSAS; Portuguese validation: Serra et al., 1982) were applied in order to determine whether patients reported higher anxiety levels than controls. ZSAS is a self-rating scale that provides a reliable measure of state anxiety level at the time of 
Table 1

Sociodemographic and clinical characteristics of patients and healthy controls

\begin{tabular}{|c|c|c|c|}
\hline & & $\begin{array}{l}\text { Psychotic } \\
\text { patients }(n=22)\end{array}$ & $\begin{array}{l}\text { Control group } \\
(n=22)\end{array}$ \\
\hline \multirow[t]{2}{*}{ Gender, $n(\%)$} & Male & $17(77.3)$ & $17(77.3)$ \\
\hline & Female & $5(22.7)$ & $5(22.7)$ \\
\hline \multicolumn{2}{|l|}{ Age $(M, S D)$} & $36.59(11.27)$ & $36.95(13.14)$ \\
\hline \multirow[t]{2}{*}{ Nationality, $n(\%)$} & Portuguese & $20(86.4)$ & $19(90.9)$ \\
\hline & Other & $2(13.6)$ & $3(9.1)$ \\
\hline \multirow{5}{*}{$\begin{array}{l}\text { Marital status, } n \\
\quad(\%)\end{array}$} & Married & $0(0)$ & $10(45.5)$ \\
\hline & Single & $18(81.8)$ & $10(45.5)$ \\
\hline & Widower & $1(4.5)$ & $0(0)$ \\
\hline & Divorced & $2(9.1)$ & $1(4.5)$ \\
\hline & Consensual union & $1(4.5)$ & $1(4.5)$ \\
\hline \multirow{3}{*}{$\begin{array}{l}\text { Educational level, } n \\
\quad(\%)\end{array}$} & Basic education & $9(40.9)$ & $0(0)$ \\
\hline & High school & $13(59.1)$ & $4(18.2)$ \\
\hline & Higher education & $0(0)$ & $18(81.8)$ \\
\hline \multirow[t]{2}{*}{ Handedness, $n(\%)$} & Right-handed & $21(95.5)$ & $21(95.5)$ \\
\hline & Left-handed & $1(4.5)$ & $1(4.5)$ \\
\hline \multirow[t]{2}{*}{ Vision, $n(\%)$} & Corrected-to-normal & $7(31.8)$ & $10(45.5)$ \\
\hline & Normal & $15(68.2)$ & $12(54.5)$ \\
\hline \multirow[t]{3}{*}{ Medication, $n(\%)$} & Atypical AP & $15(68.18)$ & - \\
\hline & $\begin{array}{l}\text { Typical and atypical } \\
\text { AP }\end{array}$ & $7(31.82)$ & - \\
\hline & Benzodiazepines & $8(36.36)$ & - \\
\hline \multicolumn{2}{|l|}{$\operatorname{BPRS}(M, S D)$} & $36.09(11.06)$ & - \\
\hline \multicolumn{2}{|c|}{ Age of diagnosis $(M, S D)$} & $27.68(9.23)$ & - \\
\hline \multicolumn{2}{|c|}{ Duration of disorder $(M, S D)$} & $8.91(8.3)$ & - \\
\hline \multicolumn{2}{|c|}{ Number of hospitalizations $(M, S D)$} & $1.64(2.19)$ & - \\
\hline
\end{tabular}

Abbreviations: AP, antipsychotic; BPRS, Brief Psychiatric Rating Scale.

assessment. The severity of psychiatric symptoms was assessed with the Portuguese version of the expanded Brief Psychiatric Rating Scale (BPRS 4.0; Portuguese version: Caldas de Almeida et al., 1996) by two experienced psychiatrists (NM, SM).

\subsection{Target-letters discrimination task}

All stimuli were presented on a white background screen. Targetletters were an $\mathrm{X}$ or an $\mathrm{N}$, displayed along with five distractor-letters which could be identical (O) or different (G, H, K, J, S or Y, randomly chosen). These stimuli were displayed in an imaginary circle around a black fixation cross, with a $2.52^{\circ}$ radius (equally likely to appear in any of the six positions). All letters were presented in black colour font type "Lucida Console", and were $0.5^{\circ}$ in width by $0.5^{\circ}$ in height.

The task-irrelevant stimuli consisted of colour photographs of human faces, presented in the parafoveal area. These were selected from the Karolinska Directed Emotional Faces (identify-numbers AF01, AF09, AF22, AF26, AM08, AM10, AM17, AM29; Lundqvist et al., 1998, http://www.facialstimuli.com/) and displayed anger, happy and neutral expressions of four Caucasian males and four Caucasian females (facing forwards). Distance from fixation point and the centre of the picture were $9.45^{\circ}$, and the size of each taskirrelevant stimulus was $6.45^{\circ}$ in width by $6.46^{\circ}$ in height.

The task was programmed using E-Prime 2.0 software (Schneider et al., 2002).

\subsection{Stroop neuropsychological screening test}

The Stroop Neuropsychological Screening Test (SNST; Portuguese version: Castro et al., 2000) was administered to assess selective attention and to determine whether psychotic patients showed lower selective attention scores, in comparison to controls. Participants were required to say the colour of the letters independently of the written word. For example, if the word 'red' was written in blue the correct answer would be 'blue'.
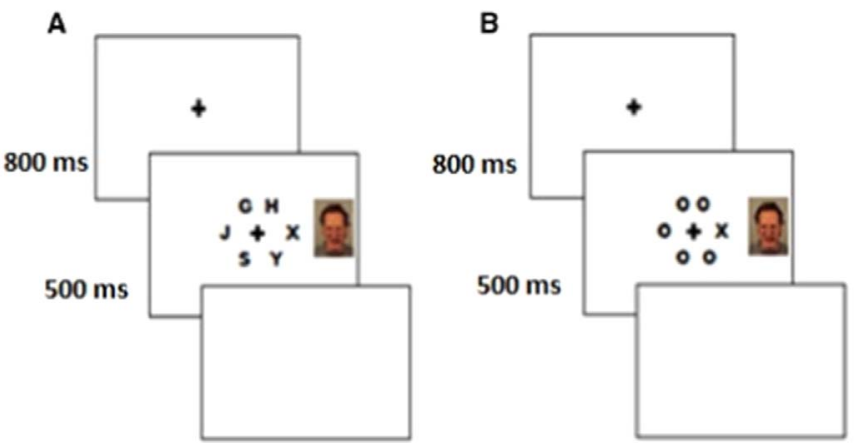

Fig. 1. Sequence of the high (A) and low (B) perceptual load conditions in the experiment.

\subsection{Procedures}

Informed consent was given. A sociodemographic questionnaire and ZSAS were filled. Participants were asked to sit comfortably at about $40 \mathrm{~cm}$ from the screen.

The discrimination-task stimuli presentation was conducted using a Samsung NP300V3A-S06PT laptop with a 13.3" monitor and the monitor had a refresh rate of $60 \mathrm{~Hz}$. The laptop was connected to the mains through a power supply cable and the brightness was adjust to 100. Participants were informed that they had to discriminate a targetletter (X or $\mathrm{N}$ ) among other distractor-letters and, simultaneously, ignore the presence of a task-irrelevant image. They should also keep their index fingers close to $\mathrm{X}$ and $\mathrm{N}$ keys in order to press, as quickly and accurate as possible, the discriminated letter button.

Each trial started with the display of a fixation cross in the centre of a white screen, randomly presented for $800 \mathrm{~ms}$ or $1200 \mathrm{~ms}$, in order to preclude anticipation effects. Immediately after, the target-letter was displayed among five "Os" (low perceptual load) or five different letters - G, H, K, J, S, Y (high perceptual load) in a circular form (Fig. 1). The letters could appear in any of the six positions (in equal probability). A task-irrelevant facial expression was displayed either left or right from fixation point (in equal probability), simultaneously with the letters (Fig. 1). Stimuli (i.e., letters and facial expression) were presented for $500 \mathrm{~ms}$. Next, a white screen was displayed until a response was obtained from the participant. The inter-trial interval was $500 \mathrm{~ms}$ long. The order of the perceptual load conditions and stimuli (i.e., emotion type, target and non-target letters) was fully randomized for each participant. Participants completed 48 practice trials, 24 for each perceptual load (equally distributed by emotion type), with accuracy feedback. None of the faces used in the practice trials were used in the experiment trials. The main experiment contained 384 trials, 192 for each perceptual load (equally distributed by emotion type) (see Gupta and Srinivasan, 2015; Gupta et al., 2016; Soares et al., 2015; Wiens and Syrjänen, 2013; for similar procedures). Response times (RT) and accuracy were analysed.

Lastly, the SNST was administered. The entire experiment (i.e., letter discrimination task and SNST) lasted approximately $45 \mathrm{~min}$.

\subsection{Design and statistical analyses}

Data were analysed with IBM SPSS Statistics 22 software. Significance levels were set at $p<0.05$ and partial $\eta^{2}\left(\eta_{p}{ }^{2}\right)$ was used as estimate of effect sizes. Student's $t$-tests were performed for age, ZSAS and SNST analysis. A mixed effects repeated measures ANOVA was conducted for RT and accuracy, with two within-subjects' factors (perceptual load and facial expression) and one between-subjects factor (group). Post-hoc tests were accomplished using Bonferroni. In order to further investigate if the differences in RT and accuracy could be age-related, we introduced age as a covariate in the second level of analyses. 
The means of RT and accuracy were calculated for each subject and condition. The analysis of RT excluded error trials (6.41\%). RT leading \pm three standard deviations away from the mean (calculated separately for each participant and condition) were replaced by $M \pm 3 \times S D$ (1.04\%).

\section{Results}

\subsection{Sample characterization}

The sample included a total of 44 participants, from 19 to 58 years old $(M=36.773, S D=12.098)$. Despite the wide age range there was no significant age difference between the patient group and healthy controls, $t(42)=-0.990, p=0.922$. However, the analysis of state anxiety showed a significant difference between groups, $t$ (36.766) $=2.701, p=0.010$. Psychotic patients reported a significantly higher state anxiety $(M=33.86, S D=6.03)$ that controls $(M=29.68, S D=4.05)$. In addition, there were significant differences between groups in selective attention, $t(34.842)=-5.059, p<0.0001$, with psychotic patients showing a significantly lower selective attention $(M=79.58$, $S D=20.33)$, compared to healthy controls $(M=105.32, S D=12.47)$.

\subsection{Response times (RT)}

The analysis of RT showed a main significant effect of perceptual load, with significantly slower RT at high load $(M=833.41, S D=35.109)$ vs low load $(M=648.887, S D=23.792), F(1,42)=54.376, p<0.0001$, $\eta_{p}{ }^{2}=0.564$, thus confirming the effectiveness of the perceptual load manipulation. Results also revealed an interaction between group and perceptual load, $F(1,42)=6.211, p=0.017, \eta_{p}{ }^{2}=0.683$, showing that the slower RTs in high perceptual load, compared to low perceptual load conditions, were enhanced in psychotic patients (see Fig. 2).

Analysis also indicated a main significant group effect, showing that RT was significantly longer ( $p s=0.002)$ for patients $(M=832.016$, $S D=38.549)$, compared to controls $(M=650.393, S D=38.549), F$ $(1,42)=11$. 099, $p=0.002, \eta_{p}{ }^{2}=0.209$. No other main effects or interactions were found $(p>0.05)$.

\subsection{Accuracy}

The analysis of accuracy showed a main effect of perceptual load, with significantly lower accuracy at high load $(M=0.900, S D=0.012)$ vs low load $(M=0.931, S D=0.011), \quad F \quad(1,42)=21.722, \quad p<0.0001$, $\eta_{p}{ }^{2}=0.341$, again confirming the effectiveness of the perceptual load manipulation. Results also revealed an interaction between group and perceptual load, $F(1,42)=4.866, p=0.033, \eta_{p}{ }^{2}=0.104$. More specifi-

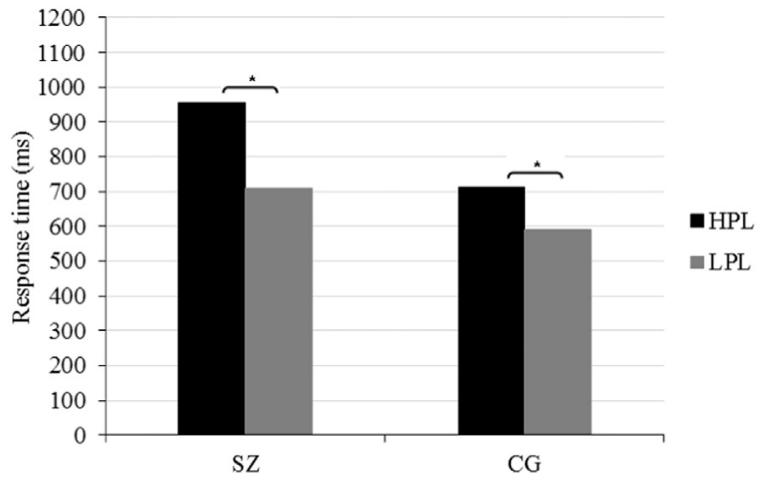

Fig. 2. Mean response times in milliseconds $(\mathrm{ms})$ to discriminate the target letter (X or $\mathrm{N}$ ) in different perceptual load conditions (high and low) as function of the group (psychotic disorder and control group). Both patients and controls tarried significantly longer to respond at high perceptual low than low perceptual load. Abbreviations: HPL, high perceptual load; LPL, low perceptual load; SZ, schizophrenia and schizoaffective patients; CG, control group. ${ }^{*} p s<0.05$.

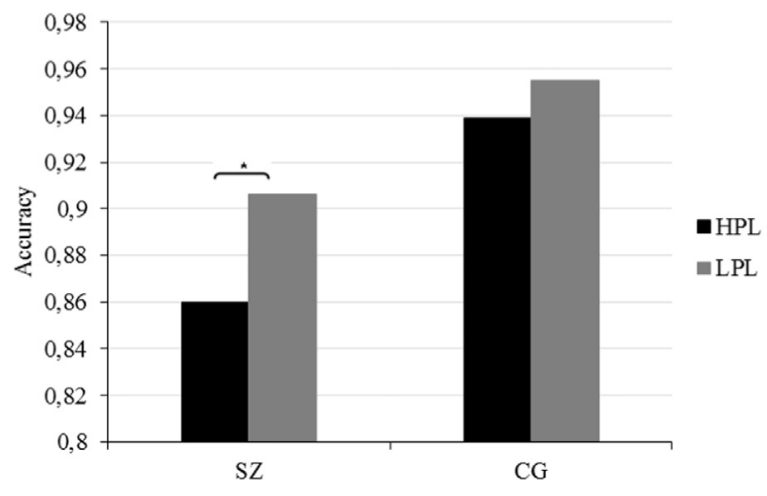

Fig. 3. Mean accuracy proportions to discriminate the target letter (X or N) in different perceptual load conditions (high or low) as function of the group (psychotic disorder and control group). Patients showed a significant lower accuracy at high load than low load. Concerning controls, the difference between load conditions was not significant. Abbreviations: HPL, high perceptual load; LPL, low perceptual load; SZ, schizophrenia and schizoaffective patients; CG, control group. ${ }^{*} p s<0.05$.

cally, patients showed a significant lower accuracy at high load vs low load ( $p s=0.009$ ), while the control group did not show any differences in accuracy between the high and low load conditions ( $p s=0.090$ ) (see Fig. 3).

An interaction between group and emotion was also found, $F(2,84)$ $=4.380, p=0.016, \eta_{p}{ }^{2}=0.094$. Patients showed a lower accuracy for happy $(M=0.874, S D=0.017)$, followed by angry $(M=0.886, S D=0.016)$ and neutral faces $(M=0.890, S D=0.015)$. Interestingly, the only significant difference in accuracy was between happy and neutral faces ( $p s=0.024)$. Regarding controls, accuracy was also lower for happy faces $(M=0.949, S D=0.017)$, followed by angry $(M=0.950, S D=0.016)$ and neutral faces $(M=0.941, S D=0.015)$, although post-hoc analysis did not reveal any significant differences ( $p s>0.050)$.

We also found an interaction between group, perceptual load and facial expression, $F(2,84)=3.755, p=0.027, \eta_{p}{ }^{2}=0.082$. At high load, patients showed significantly higher accuracy for neutral and angry faces rather than happy faces, $(p s<0.050)$. At low load, accuracy was higher, but not significant ( $p s>0.050$ ), for neutral faces, followed by happy and angry faces (see Fig. 4). As for controls, their accuracy at high load was slightly higher for happy faces, followed by angry and neutral faces. At low load, accuracy was higher for angry faces, followed by neutral and happy faces. However, post-hoc analysis did not reveal any significant difference for controls between facial expressions in the same load condition ( $p s>0.050$ ) (Fig. 5). Additionally, patients showed significantly lower accuracy in all facial expressions at high load, compared to low load conditions $(p s<0.050)$. In contrast, this effect was not observed in controls $(p s>0.050)$. Post-hoc analysis also

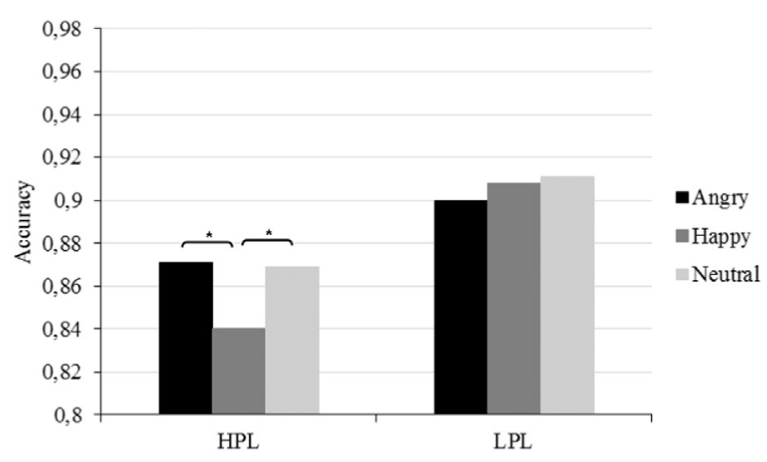

Fig. 4. Mean accuracy proportions for psychotic patients to discriminate the target letter (X or N) in different facial expressions conditions (angry, happy and neutral) as function of the perceptual load (high and low). Patients showed a significant higher accuracy for neutral and angry faces, compared to happy faces, at high load. No more significant differences were found. Abbreviations: HPL, high perceptual load; LPL, low perceptual load. ${ }^{*} p s<0.05$. 


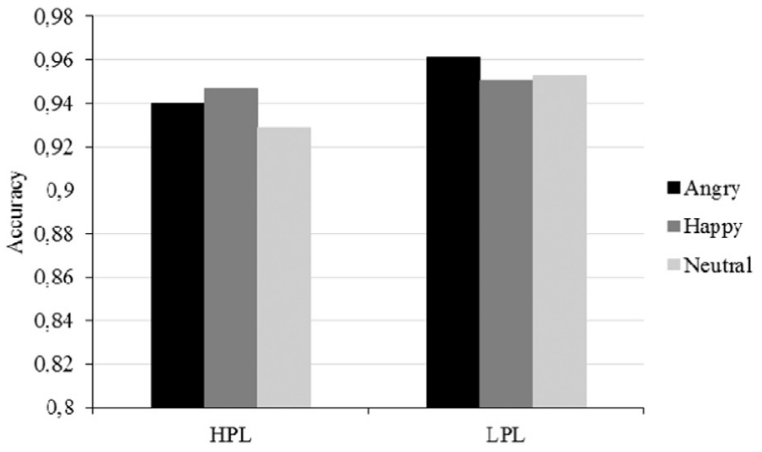

Fig. 5. Mean accuracy proportions for the control group to discriminate the target letter (X or N) in different facial expressions conditions (angry, happy and neutral) as function of the perceptual load (high and low). No significant differences were found in controls between facial expressions in the same load conditions. Abbreviations: HPL, high perceptual load; LPL, low perceptual load.

revealed that at high load accuracy was significantly lower in all facial expressions for patients compared to controls $(p s<0.050)$. However, the only significant difference in the Bonferroni tests between patients and controls at low load was shown for angry faces ( $p s=0.017)$.

Finally, the results indicated a main significant group effect, showing that accuracy was significantly lower for patients $(M=0.883$, $S D=0.016)$ than controls $(M=0.947, S D=0.016), F(1,42)=8.200$, $p=0.007, \eta_{p}{ }^{2}=0.163$. No other main effects or interactions were found $(p>0.050)$.

\subsection{Analysis of covariance}

Given the wide age range in our population, we conducted an ANCOVA, including age as a covariate. The analysis showed that after controlling for the effects of age on RT, $F(1,41)=6.137, p=0.017$, $\eta_{p}{ }^{2}=0.130$, the main effect of group, $F(1,41)=12.721, p=0.010$, $\eta_{p}{ }^{2}=0.237$, and group $x$ perceptual load interaction, $F(1,41)=6.293$, $p=0.016, \quad \eta_{p}{ }^{2}=0.133$, remained both statistically significant. Consistently, for accuracy it was shown that after controlling for the effects of age, $F(1,41)=0.050, p=0.825, \eta_{p}{ }^{2}=0.001$, the main effect of group, $F(1,41)=7.993, p=0.007, \eta_{p}{ }^{2}=0.163$, group $x$ perceptual load interaction, $F(1,41)=5.209, p=0.028, \eta_{p}{ }^{2}=0.113$, group $x$ facial expression interaction, $F(2,82)=4.312, p=0.017, \eta_{p}{ }^{2}=0.095$, and group $x$ facial expression $x$ perceptual load interaction, $F(2,82)$ $=3.690, p=0.029, \eta_{p}{ }^{2}=0.083$, all remained statistically significant.

\section{Discussion}

In the present study we examined whether psychotic patients, compared to healthy controls, were more prone to interference by emotional facial expressions while engaged in a letter discrimination task involving different levels of perceptual load (Foster and Lavie, 2008). Although some studies have investigated the effects of perceptual load in psychotic disorders (e.g., Ducato et al., 2008), only nonemotional distractors have been included. Therefore, in the present study we used facial expressions, which are biologically significant stimuli (see Öhman, 2009; Öhman et al., 2012) and essential for understanding impairments in social functioning in psychotic disorders (e.g., Couture et al., 2006; Madeira et al., 2016).

The results showed that overall there was a greater interference of task-irrelevant stimuli at high load (i.e., slower RT and lower accuracy), which is consistent with previous studies using human faces as distractors and suggesting that such stimuli capture attention even when cognitive resources are engaged in other tasks (Öhman et al., 2012). Importantly and as hypothesised, psychotic patients had significantly worse attentional performance than healthy controls. However, although patients showed overall slower RTs, the effort to solve the task did not lead to higher accuracy rates (in comparison with controls). In fact, patients were significantly less accurate than healthy controls in the main task. The pattern of results was maintained even when controlling for the effects of age. The results of the SNST corroborate this finding by revealing that patients had greater difficulties in ignoring task-irrelevant information during colour nomination, when compared to controls. These findings support previous studies with non-emotional distractors, indicating that psychotic patients are more prone to the interference of task-irrelevant stimuli (e.g., Demeter et al., 2013; Fuller et al., 2000; Henik and Salo, 2004; Ungar et al., 2010).

The results from the present study also showed that the emotional task-irrelevant stimuli (human faces) were processed even under high task demands by psychotic individuals. This confirms our initial hypothesis but is in contrast with the study by Ducato et al. (2008). According to the authors, psychotic patients have fewer attentional resources, which in turn lead to less interference of task-irrelevant stimuli at medium and high perpetual load, compared to controls. However, only non-emotional task-irrelevant stimuli were used in their study. It is well known that human faces represent potential social cues and that the ability to recognise, identify and express emotions is impaired in psychotic disorders (e.g., Addington and Addington, 1998; Kohler et al., 2000, 2010; Losiak and Siedlecka, 2013; Penn et al., 2008). Therefore, it is possible that the fewer attentional resources available in psychotic individuals, compared to healthy individuals (Granholm et al.,1997), were used to recognise the emotional faces rather than to process the task-relevant stimuli, hence leading to a worse performance in the attentional task.

In healthy controls, the results showed a non-significant difference in effectiveness (i.e., performance quality evaluated by accuracy) between the two load conditions. Controls were able to avoid the interference of emotional task-irrelevant stimuli even when the attentional task demanded higher attentional resources, suggesting that attentional control was not affected. In contrast, patients were significantly less effective when the task was more demanding. Indeed, attentional control plays an important role in the inhibition of irrelevant information (Forster and Lavie, 2008), with our results suggesting a deficit in these processes in psychotic disorders, which is consistent with previous studies (e.g., Fuller et al. 2006; Hahn et al., 2010; Mitchell and Rossell, 2014). Also consistent with this, are our findings that psychotic patients had significantly higher state-anxiety levels prior to the attentional task, compared to healthy individuals. According to the Attentional Control Theory (Eysenck et al., 2007), anxiety reduces attentional control. Since anxiety symptoms are highly prevalent among patients with psychotic disorders (e.g., Karpov et al., 2016; Park et al., 2016), as corroborated by our study, it is possible that the impairments in attentional control were somewhat related to state anxiety. Soares et al. (2015) examined the interference of emotional face task-irrelevant stimuli on attentional control processes in social anxiety, through a manipulation of perceptual load (using a similar attentional task to the one used in our study). The authors postulated that individuals exhibiting high social anxiety were more prone to distraction by task-irrelevant stimuli, especially under high perceptual load conditions. Regarding psychotic patients, a similar effect was found in the present study, suggesting the importance to always consider the interference of specific symptoms, such as anxiety, in attentional control impairments.

Finally, we also observed differences in effectiveness in both groups depending on the emotion displayed in the face and the perceptual load involved in the task. Patients' accuracy was significantly lower for happy faces than for angry and neutral faces, at high load. Thus, disproving our hypothesis, when the task demanded higher attentional resources, negative and neutral social cues caused less interference in effectiveness. Angry faces are forms of human hostility and potential threat. Evolutionary relevant stimuli related to potential threat (e.g., angry and fear faces) tend to be processed quickly and effectively, and without the need of conscious awareness (see Öhman, 2009). 
According to LeDoux (2002), information about potentially threatening stimuli is transmitted directly from the thalamus to the amygdala, allowing a reaction to an ambiguous stimulus before the individual has identified it as threatening (e.g., snake) or harmless (e.g., branch). Thus, threatening social stimuli should have shifted the attention of the task-relevant stimuli in psychotic patients, leading to a worse attentional performance. Contrarily, our results suggest that the weaker recognition of threatening faces in psychotic disorder (e.g., Bediou et al., 2005; Leppänen et al., 2006; Namiki et al., 2007; Pinkham et al., 2014) may have influenced the detection of potential social threat, leading to a lower impact of task-irrelevant angry faces during the attentional task. A previous study used an emotional Stroop task and found that patients with deficit syndrome took longer to name the colour of a neutral word when it was immediately preceded by a negative word, thus revealing difficulties in disengaging attention from unpleasant stimuli (Strauss et al., 2008). Our findings showed greater interference with a positive rather than negative stimuli; this difference in results might be because Strauss et al. used words with positive and negative valence rather than face expressions, which are a social stimulus. According to Pinkham et al. (2014), schizophrenia patients have impairments in detecting threatening social information (i.e., angry faces) but their ability to detect threatening non-social stimuli (i.e., snakes) remains intact. However, additional studies should directly compare emotional with non-emotional stimuli (facial or non-facial) in order to determine whether the dissociations in processing positive vs negative emotional material by psychotic individuals are restricted to a stimulus category.

Our findings that for psychotic patients happy faces pose significantly higher interference under high load conditions compared to neutral faces, are consistent with those found in the study by Park et al. (2011), which revealed a steeper sensitivity decline over time in psychotic patients when the relevant stimuli were displayed with a happy expression, as compared to a sad expression. The authors suggested that due to the greater impairment in recognising happy faces (e.g., Laroi et al., 2010; Tsoi et al., 2008), these stimuli consumed attentional resources needed to perform the task. Park et al. did not use angry faces and, as previously mentioned, angry faces represent a form of human hostility and a crucial evolutionary threat signal (see Öhman, 2009, Öhman et al., 2012). Psychotic disorders are related to a predominantly sense of threat and danger related with maladaptive appraisals of somehow anomalous experiences (e.g., Underwood et al., 2016). Therefore, it is possible to speculate that psychotic patients show a phenomenon of sensitisation to threat and that angry faces do not have a marked effect. Moreover, in a recent study, Huang et al. (2011) showed that schizophrenia patients tend to categorise intermediate angry expressions as happy, proposing a poor perception bias to these stimuli. However, when the faces reached certain intensity, perception from patients changed more quickly when compared to controls. According to the authors, patients may decrease the valence of threatening facial expressions in order to regulate affect, as a part of a response strategy. Since the study was conducted with Chinese participants, comparisons should be done with caution.

Despite the findings that threatening expressions are processed preferentially, previous research performed in healthy individuals have showed that happy expressions are easier to categorise due to highly salient features (e.g., smile) (e.g., Calvo and Beltrán, 2013; Calvo and Lundqvist, 2008). For example, Smith and Schyns (2009) showed that happy and surprise expressions are recognised easier than sad, angry, fearful and disgust expressions, even over a wide range of viewing distances. However, according to a recent meta-analysis (Nummenmaa \& Calvo, 2015; see also Becker and Srinivasan, 2014), the authors conclude that the robust happy advantage found in many studies with healthy individuals seems to reflect its affective valence and not lowlevel visual features. Nevertheless, future research should carefully control for the visual conspicuity of the facial stimuli (e.g., luminance, contrast, spatial frequency) in order to disentangle if the dissociations in processing emotional social stimuli should solely be attributed to emotional factors, and whether visual information has an additive effect in studies using clinical samples. In the present study, the easier categorisation of happy faces may have contributed to attentional bias towards happy faces in psychotic individuals (see Edwards et al., 2002). On the other hand, and as a consequence of the emotional impairments in psychotic disorders, namely in mentalizing, i.e., in understanding the intensions of others (e.g., Bora et al., 2009a), it is possible that positive social cues (e.g., happy faces) might have been perceived and interpreted in a threatening manner by psychotic individuals, hence leading to a perception bias of positive stimuli. The ability to interpret and respond accordingly to facial expressions is crucial for healthy social interactions (e.g., Morris et al., 2009). A better understanding of these impairments may have major implications for the social rehabilitation of patients. For example, Combs et al. (2011) revealed that when schizophrenia patients are trained to focus attention on emotional faces through attention shaping programs, their emotional perception improves.

A number of limitations of our study should be noted. First, view of our small sample size, the results should be interpreted with caution. Future studies should address this issue in larger samples, allowing the manipulation of different variables as state anxiety and symptoms category, namely, the negative sub syndrome (Addington and Addington, 1997; Mitchell and Rossell, 2014; Nieuwenstein et al., 2001; Strauss et al., 2008, 2011). In the current study, $81.8 \%$ of healthy controls had higher education level, while none of the patients achieved this educational level. Controls may have considered the discrimination task easier, compared to patients, increasing performance differences between groups, especially under high perceptual load. In addition, most participants were male, which may have influenced the perception of emotional traits in female faces.

A further limitation is that we did not include trials with taskirrelevant non-emotional stimuli, which makes it difficult for us to accurately assess the degree of interference from emotional distracters; adding such trials could enhance random answers, besides making the duration of the experiment excessively long. Nonetheless, additional research would benefit from the inclusion of a facial recognition task, in order to verify if patients' effectiveness was in fact influenced by the valence of the distractor.

All patients were medicated with antipsychotics at the time of evaluation; however, available evidence suggests a positive influence of atypical antipsychotics in attentional processes, improving deficits already present in untreated first-episode patients (e.g., Keedy et al., 2015; Kucharska-Pietura et al., 2012). Further studies should also control for effects of medication.

Another potential limitation of the present study is the inclusion of patients with schizoaffective disorder, since the presence of affective symptoms can affect emotional recognition differently when compared to schizophrenia. In future studies, focus on a pure diagnostic category may improve methodological robustness but the inclusion of schizoaffective patients is not entirely inappropriate. Cognitive functioning in schizoaffective disorder is much less studied compared with schizophrenia; yet, a meta-analysis of the available data that directly compared cognitive functioning across schizophrenia, schizoaffective disorder and affective psychosis did not provide evidence for categorical differences between schizophrenia and other groups, in line with recent findings from genetic studies which have reignited the debate about the validity of Kraepelin's classification of the major psychoses (Bora et al., 2009b). It would be also important to study whether there are significant differences in attentional performance in psychotic disorders over other severe mental illnesses such as bipolar disorder (e.g., Addington and Addington, 1997; Bozikas et al., 2005).

There is reasonable evidence that cognitive dysfunction experienced by people with psychotic disorders can improve; our findings provide relevant information for the development of improved and personalised cognitive remediation techniques, that take into account partici- 
pant characteristics (Wykes and Spaulding, 2011). A recent statement from the International Consortium on Hallucinations Research identified several key directions in future research on psychological therapies targeting auditory hallucinations, such as moving beyond the focus on overall efficacy to understand specific therapeutic processes targeting voices, better addressing the psychological processes associated with voices such as cognitive mechanisms, besides understanding individual differences among voice hearers (Thomas et al., 2014). A more accurate understanding of the contribution of perception load in psychotic symptomatology could also benefit cognitive-behavioural psychotherapeutic interventions. A study on the effects of perceptual load on bias generation associated with schizotypal traits (Tsakanikos, 2006) found that overall perceptual biases were a positive function of perceptual load, although psychotic-like perceptual biases were only observed under conditions of medium perceptual load. Tsakanikos hypothesises that, if such cognitive biases were responsible for the maintenance of certain positive symptoms of schizophrenia, a voluntary increase in perceptual load (namely carrying out a cognitively demanding task during a hallucinatory experience) could have a detrimental effect on the intensity of such symptoms and that the identification of parameters that modulate perceptual biases in clinical practice could enhance our understanding about the formation and the maintenance of hallucinations.

The present study provides a further insight into our understanding of psychotic disorders by examining the influence of perceptual load in the processing of facial distractors. Psychotic patients showed impairments in attentional control, particularly towards happy expressions. They also tended to refrain from allocating salience towards neutral and threatening social cues. These results underline the need of a more detailed investigation of attentional impairments in social context in psychotic disorders.

\section{Role of the funding source}

There was no external funding for this study.

\section{Conflict of interest}

NM has served as a consultant or advisory board member for AstraZeneca, Ferrer and Janssen. All authors report no conflicts of interest.

\section{Contributors}

JG participated in the conception and design of the study, carried out the data collection, analysis and interpretation of the data, and performed the first draft of the manuscript. SCS participated in the conception and design of the study, supervised the data collection and analysis, and contributed to the writing of the manuscript. PR performed part of the task design and contributed to the writing of the manuscript. SM participated in patient recruitment and helped to review the manuscript. NM participated in the conception and design of the study, supervised the data collection and analysis, and contributed to the writing of the manuscript. All authors read and approved the final manuscript.

\section{Acknowledgements}

We thank Carolina Roque, Cristina Pereira, Vítor Santos and Tiago Santos for their assistance with data collection. We also thank Licínio Craveiro for his critical comments and English language review of the manuscript. We gratefully acknowledge all of the individuals who participated in the present study.

\section{References}

Addington, J., Addington, D., 1997. Attentional vulnerability indicators in schizophrenia and bipolar disorder. Schizophr. Res. 23 (3), 197-204.

Addington, J., Addington, D., 1998. Facial affect recognition and information processing in schizophrenia and bipolar disorder. Schizophr. Res. 32 (3), 171-181.

American Psychiatric Association (APA), 2013. Diagnostic and Statistical Manual of Mental Disorders 5th ed.. American Psychiatric Publishing, Washington, D.C.

Amorim, P., 2000. Mini International Neuropsychiatric Interview (MINI): Validação de entrevista breve para diagnóstico de transtornos mentais. Rev. Bras. Psiquiatr. 22 (3), 106-115.

Becker, D.V., Srinivasan, N., 2014. The vividness of the happy face. Curr. Dir. Psychol. Sci. 23 (3), 189-194. http://dx.doi.org/10.1177/0963721414533702.

Bediou, B., Franck, N., Saoud, M., Baudouin, J.Y., Tiberghien, G., Dalery, J., d'Amato, T. 2005. Effects of emotion and identity on facial affect processing in schizophrenia. Psychiatry Res. 133 (2-3), 149-157. http://dx.doi.org/10.1016/ j.psychres.2004.08.008.

Bleuler, E., 1950. Dementia Praecox or the Group of Schizophrenias. International Universities Press, New York.

Bozikas, V.P., Andreou, C., Giannakou, M., Tonia, T., Anezoulaki, D., Karavatos, A., Fokas, K., Kosmidis, M.H., 2005. Deficits in sustained attention in schizophrenia but not in bipolar disorder. Schizophr. Res. 78 (2-3), 225-233. http://dx.doi.org/ 10.1016/j.schres.2005.05.014.

Bora, E., Yucel, M., Pantelis, C., 2009a. Theory of mind impairment in schizophrenia: meta-analysis. Schizophr. Res. 109 (1), 1-9. http://dx.doi.org/10.1016/ j.schres.2008.12.020.

Bora, E., Yucel, M., Pantelis, C., 2009b. Cognitive functioning in schizophrenia, schizoaffective disorder and affective psychoses: meta-analytic study. Br. J. Psychiatry 195 (6), 475-482. http://dx.doi.org/10.1192/bjp.bp.108.055731.

Caldas de Almeida, J.M., Gusmão, R., Talina, M., Xavier, M., 1996. Brief Psychiatric Rating Scale (BPRS) Versão Ampliada (4.0) Portuguesa: Escala, pontos de ancoragem e manual de administração. Psychiatric and Mental Health Department São Francisco Xavier Hospital, Lisbon.

Calvo, M.G., Beltrán, D., 2013. Recognition advantage of happy faces: tracing the neurocognitive processes. Neuropsychologia 51 (11), 2051-2060. http://dx.doi.org/ 10.1016/j.neuropsychologia.2013.07.010.

Calvo, M.G., Lundqvist, D., 2008. Facial expressions of emotion (KDEF): identification under different display-duration conditions. Behav. Res. Methods 40 (1), 109-115. http://dx.doi.org/10.3758/BRM.40.1.109.

Castro, S.L., Martins, L., Cunha, L.S., 2000. Stroop Neuropsicológico Português. On-line material. Center of Psychology, University of Porto, Porto.

Combs, D.R., Champan, D., Waguspack, J., Basso, M.R., Penn, D.L., 2011. Attention shaping as means to improve emotion perception deficits in outpatients with schizophrenia and impaired controls. Schizophr. Res. 127 (1-3), 151-156. http:// dx.doi.org/10.1016/j.schres.2010.05.011.

Couture, S.M., Penn, D.L., Roberts, D.L., 2006. The functional significance of social cognition in schizophrenia: a review. Schizophr. Bull. 32 (1), 44-63. http:// dx.doi.org/10.1093/schbul/sbl029.

Delvecchio, G., Sugranyes, G., Frangou, S., 2013. Evidence of diagnostic specificity in the neural correlates of facial affect processing in bipolar disorder and schizophrenia: a meta-analysis of functional imaging studies. Psychol. Med. 43 (3), 553-569 http:// dx.doi.org/10.1017/S0033291712001432.

Demeter, E., Guthrie, S.K., Taylor, S.F., Sarter, M., Lustig, C., 2013. Increased distrator vulnerability but preserved vigilance in patients with schizophrenia: evidence from a translational sustained attention task. Schizophr. Res. 144 (1-3), 136-141. http:// dx.doi.org/10.1016/j.schres.2013.01.003.

Ducato, M.G., Thomas, P., Monestes, J.L., Despretz, P., Boucart, M., 2008. Attentional capture in schizophrenia and schizotypy: Effect of attentional load. Cognit. Neuropsychiatry 13 (2), 89-111. http://dx.doi.org/10.1080/13546800701707371.

Edwards, J., Jackson, H.J., Pattison, P.E., 2002. Emotion recognition via facial expression and affective prosody in schizophrenia: a methodological review. Clin. Psychol. Rev. 22, 789-832.

Eysenck, M.W., Derakshan, N., Santos, R., Calvo, M.G., 2007. Anxiety and cognitive performance: attentional control theory. Emotion 7 (2), 336-353.

Foster, S., Lavie, N., 2008. Attentional capture by entirely irrelevant distractors. Vis. Cognit. 16 (2-3), 200-214. http://dx.doi.org/10.1080/13506280701465049.

Fuller, R., Frith, C.D., Jahanshahi, M., 2000. Reduced negative priming does indicate reduced cognitive inhibition in schizophrenia. Cognit. Neuropsychiatry 5 (1), 21-35. http://dx.doi.org/10.1080/135468000395808.

Fuller, R.L., Luck, S.J., Braun, E.L., Robinson, B.M., McMahon, R.P., Gold, J.M., 2006. Impaired control of visual attention in schizophrenia. J. Abnorm. Psychol. 115 (2), 266-275. http://dx.doi.org/10.1037/0021-843X.115.2.266.

Gold, J.M., Fuller, R.L., Robinson, B.M., Braun, E.L., Luck, S.J., 2007. Impaired topdown control of visual search in schizophrenia. Schizophr. Res. 94 (1-3), 148-155. http://dx.doi.org/10.1016/j.schres.2007.04.023.

Granholm, E., Morris, S.K., Sarkin, A.J., Asarnow, R.F., Jeste, D.V., 1997. Pupillary responses index overload of working memory resources in schizophrenia. J. Abnorm. Psychol. 106 (3), 458-467.

Green, M.F., Bearden, C.E., Cannon, T.D., Fiske, A.P., Hellemann, G.S., Horan, W.P., Kee, K., Sergi, M.J., Subotnik, K.L., Sugar, C.A., Ventura, J., Yee, C.M., Nuechterlein, K.H., 2012. Social cognition in schizophrenia, part 1: Performance across phase of illness. Schizophr. Bull. 38 (4), 854-864. http://dx.doi.org/10.1093/schbul/sbq171.

Green, M.F., Horan, W.P., Lee, J., 2015. Social cognition in schizophrenia. Nat. Rev. Neurosci. 16, 620-631. http://dx.doi.org/10.1038/nrn4005.

Gupta, R., Srinivasan, N., 2015. Only irrelevant sad but not happy faces are inhibited 
under high perceptual load. Cognit. Emot. 29 (4), 747-754. http://dx.doi.org/ 10.1080/02699931.2014.933735.

Gupta, R., Young-Jin, H., Lavie, N., 2016. Distrated by pleasure: effects of positive versus negative valence on emotional capture under load. Emotion 16 (3), 328-337.

Hahn, B., Robinson, B.M., Kaiser, S.T., Harvey, A.N., Beck, V.M., Leonard, C.J., Kappenman, E.S., Luck, S.J., Gold, J.M., 2010. Failure of schizophrenia patients to overcome salient distractors during working memory encoding. Biol. Psychiatry 68 (7), 603-609. http://dx.doi.org/10.1016/j.biopsych.2010.04.014.

Hansen, C.H., Hansen, R.D., 1988. Finding the face in the crowd: an anger superiority effect. J. Personal. Social Psychol. 54 (6), 917-924.

Henik, A., Salo, R., 2004. Schizophrenia and the stroop effect. Behav. Cognit. Neurosci. Rev. 3 (1), 42-59. http://dx.doi.org/10.1177/1534582304263252.

Huang, J., Chan, R., Gollan, J.K., Liu, W., Ma, Z., Li., Z., Gong, Q., 2011. Perceptual bias of patients with schizophrenia in morphed facial expressions. Psychiatry Res. 185 (1-2), 60-65. http://dx.doi.org/10.1016/j.psychres.2010.05.017.

Karpov, B., Joffe, G., Aaltonen, K., Suvisaari, J., Baryshnikov, I., Näätänen, P., Paunio, T., Isometsä, E., 2016. Anxiety symptoms in a major mood and schizophrenia spectrum disorders. Eur. Psychiatry 37, 1-7. http://dx.doi.org/10.1016/j.eurpsy.2016.04.007.

Keedy, S.K., Reilly, J.L., Bishop, J.R., Weiden, P.J., Sweeney, J.A., 2015. Impact of antipsychotic treatment on attention and motor learning systems in first-episode schizophrenia. Schizophr. Bull. 41 (2), 355-365. http://dx.doi.org/10.1093/schbul/ sbu071.

Kohler, C., Bilker, W., Hagendoorn, M., Gur, R.E., Gur, R.C., 2000. Emotion recognition deficit in schizophrenia: association with symptomatology and cognition. Biol. Psychiatry 48, 127-136.

Kohler, C., Walker, J.B., Martin, E.A., Healey, K., Moberg, P.J., 2010. Facial emotion perception in schizophrenia: a meta-analytic review. Schizophr. Bull. 36 (5), 1009-1019. http://dx.doi.org/10.1093/schbul/sbn192.

Kucharska-Pietura, K., Tylec, A., Czernikiewicsz, A., Mortimer, A., 2012. Attentional and emotional functioning in schizophrenia patients treated with conventional and atypical antipsychotic drugs. Med. Sci. Monit. 18 (1), 44-49. http://dx.doi.org/ 10.12659/MSM.882202.

Kurtz, M.M., Mueser, K.T., Thime, W.R., Corbera, S., Wexler, B.E., 2015. Social skills training and computer-assisted cognitive remediation in schizophrenia. Schizophr. Res. 162 (1-3), 35-41. http://dx.doi.org/10.1016/j.schres.2015.01.020.

Laroi, F., Fonteneau, B., Mourad, H., Raballo, A., 2010. Recognition and psychopathology in schizophrenia. J. Nerv. Ment. Dis. 198 (1), 79-81. http:// dx.doi.org/10.1097/NMD.0b013e3181c84cb0.

Lavie, N., 1995. Perceptual load as a necessary condition for selective attention. J. Exp. Psychol. Hum. Percept. Perform. 21 (3), 451-468.

Lavie, N., 2005. Distracted and confused?: Selective attention under load. Cognit. Sci. 9 (2), 75-82. http://dx.doi.org/10.1016/j.tics.2004.12.004.

Lavie, N., Ro, T., Russel, C., 2003. The role of perceptual load in processing distrator faces. Psychol. Sci. 14 (5), 510-515.

LeDoux, J., 2002. O cérebro emocional: as misteriosas estruturas da vida emocional. Pergaminho, Cascais.

Leppänen, J.M., Niehaus, D.J., Koen, L., Du Toit, E., Schoeman, R., Emsley, R., 2006. Emotional face processing deficit in schizophrenia: a replication study in a South African Xhosa population. Schizophr. Res. 84 (2-3), 323-330. http://dx.doi.org/ 10.1016/j.schres.2006.02.007.

Lin, I., Fan, S., Huang, T., Wu, W., Li, S., 2013. The associations between visual attention and facial expression identification in patients with schizophrenia. Psychiatry Investig. 10 (4), 393-398. http://dx.doi.org/10.4306/pi.2013.10.4.393.

Losiak, W., Siedlecka, J., 2013. Recognition of facial expressions of emotions in schizophrenia. Pol. Psychol. Bull. 44 (2), 232-238. http://dx.doi.org/10.2478/ppb2013-0026.

Luck, S.J., Gold, J.M., 2008. The construct of attention in schizophrenia. Biol. Psychiatry 64 (1), 34-39. http://dx.doi.org/10.1016/j.biopsych.2008.02.014.

Lundqvist, D., Flykt, A., Öhman, A., 1998. Karolinska Directed Emotional Faces. CD, Section of psychology, Karolinska Institute and Hospital, Stockholm.

Madeira, N., Caldeira, S., Bajouco, M., Pereira, A.T., Martins, M.J., Macedo, A., 2016. Social cognition, negative symptoms and psychosocial functioning in schizophrenia. Int. J. Clin. Neurosci. Ment. Health 3, 1. http://dx.doi.org/10.21035/ ijenmh.2016.3.1.

Mitchell, R.L., Rossell, S.L., 2014. Perception of emotion-related conflict in human communications: what are the effects of schizophrenia? Psychiatry Res. 220 (1-2), 135-144. http://dx.doi.org/10.1016/j.psychres.2014.07.077.

Mori, S., Tanaka, G., Ayaka, Y., Michitsuji, S., Niwa, H., Uemura, M., Ohta, Y., 1996. Preattentive and focal attentional processes in schizophrenia: avisual search study. Schizophr. Res. 22 (1), 69-76.

Morris, R.W., Weicker, C.S., Loughland, C.M., 2009. Emotional face processing in schizophrenia. Curr. Opin. Psychiatry 22 (2), 140-146. http://dx.doi.org/10.1097/ YCO.0b013e328324f895.

Namiki, C., Hirao, K., Yamada, M., Hanakawa, T., Fukuyama, H., Hayashi, T., Murai, T., 2007. Impaired facial emotion recognition and reduced amygdalar volume in schizophrenia. Psychiatry Res. Neuroimaging 156 (1), 23-32. http://dx.doi.org/ 10.1016/j.pscychresns.2007.03.004.

Nieuwenstein, M.R., Aleman, A., Hann, E.H., 2001. Relationship between symptom dimensions and neurocognitive functioning in schizophrenia: a meta-analysis of WCST and CPT studies. J. Psychiatric Res. 35 (2), 119-125. http://dx.doi.org/ 10.1016/S0022-3956(01)00014-0.

Nummenmaa, L., Calvo, M.G., 2015. Dissociation between recognition and detection advantage for facial expressions: a meta-analysis. Emotion 15 (2), 243-256. http:// dx.doi.org/10.1037/emo0000042.

Öhman, A., 2009. Of snakes and faces: an evolutionary perspective on the psychology of fear. Scand. J. Psychol. 50, 543-552. http://dx.doi.org/10.1111/j.14679450.2009.00784.x.

Öhman, A., Flykt, A., Esteves, F., 2001a. Emotion driver attention: detecting the snake in the grass. J. Exp. Psychol. 130 (3), 466-478. http://dx.doi.org/10.1037/AXJ963445.130.3.466.

Öhman, A., Lundqvist, D., Esteves, F., 2001b. The face in the crowd revisited: a threat advantage with schematic stimuli. J. Personal. Soc. Psychol. 80 (3), 381-396. http:// dx.doi.org/10.1037//0022-3514.80.3.381.

Öhman, A., Soares, S.C., Juth, P., Lindström, B., Esteves, F., 2012. Evolutionary derived modulations of attention to two common fear stimuli: serpents and hostile humans. J. Cognit. Psychol. 24 (1), 17-32. http://dx.doi.org/10.1080/ 20445911.2011.629603.

Park, I., Jung, D.C., Hwang, S.S., Jung, H.Y., Yoon, J., Kin, C., Ahn, Y.M., Kim, Y.S., 2016. Longitudinal relationship between personal and social performance (PSP) and anxiety symptoms in schizophrenia. J. Affect. Disord. 190, 12-18. http://dx.doi.org/ 10.1016/j.jad.2015.09.04801650327.

Park, S., Kim, J., Kim, C., Kim, J.H., Lee, K., 2011. Sustained attention in the context of emotional processing in patients with schizophrenia. Psychiatry Res. 187 (1-2), 18-23. http://dx.doi.org/10.1016/j.psychres.2010.11.007.

Park, S., Noh, J., Kim, J.H., Lee, J., Park, J.Y., Lee, Y.R., Kim, C.H., Lee, K., 2012. Interactive effects of background facial emotion stimulus and target salience on sustained attention performance in schizophrenia. Schizophr. Res. 135 (1-3), 90-94 . http://dx.doi.org/10.1016/j.schres.2011.11.019.

Penn, D.L., Sanna, L.,J., Roberts, D.L., 2008. Social cognition in schizophrenia: an overview. Schizophr. Bull. 34 (3), 408-411. http://dx.doi.org/10.1093/schbul/ sbn014.

Perälä, J., 2013. Epidemiology of Psychotic Disorders (Academic Dissertation). National Institute for Health and Welfare (THL), Helsinki.

Pinkham, A.E., Sasson, N.J., Kelsven, S., Simpson, C.E., Healey, K., Kohler, C., 2014. An intact threat superiority effect of nonsocial but not social stimuli in schizophrenia. J. Abnorm. Psychol. 123 (1), 168-177. http://dx.doi.org/10.1037/a0035639.

Savla, G.N., Vella, L., Armstrong, C.C., Penn, D.L., Twamley, E.W., 2013. Deficits in domains of social cognition in schizophrenia: a meta-analysis of the empirical evidence. Schizophr. Bull. 39 (5), 979-992. http://dx.doi.org/10.1093/schbul/ sbs080.

Schneider, W., Eshman, A., Zuccolotto, A., 2002. E-Prime: A User's Guide. Psychology Software Tools, Pittsburgh.

Serra, A.V., Ponciano, E., Relvas, J., 1982. Aferição da escala de auto-avaliação da ansiedade-estado de Zung, numa amostra da população portuguesa: Sua avaliação como instrumento de medida. Psiquiatr. Clín. 3 (4), 203-213.

Smith, F.W., Schyns, P.G., 2009. Smile through your fear and sadness: transmitting and identifying facial expression signal over a range of viewing distances. Psychol. Sci. 20 (10), 1202-1208.

Soares, S.C., Rocha, M., Neiva, T., Rodrigues, P., Silva, C.F., 2015. Social anxiety under load: the effects of perceptual load in processing emotional faces. Front. Psychol., 6-479. http://dx.doi.org/10.3389/fpsyg.2015.00479.

Strauss, G.P., Allen, D.N., Duke, L.A., Ross, S.A., Schwartz, J., 2008. Automatic affective processing impairments in patients with deficit syndrome schizophrenia. Schizophr. Res. 102 (1-3), 76-87. http://dx.doi.org/10.1016/j.schres.2008.01.014.

Strauss, G.P., Llerena, K., Gold, J.M., 2011. Attentional disengagement from emotiona stimuli in schizophrenia. Schizophr. Res. 131 (1-3), 219-223. http://dx.doi.org/ 10.1016/j.schres.2011.06.001

Tanaka, G., Mori, S., Inadomi, H., Hamada, Y., Ohta, Y., Ozawa, H., 2007. Clear distinction between preattentive and attentive process in schizophrenia by visual search performance. Psychiatry Res. 149 (1-3), 25-31. http://dx.doi.org/10.1016/ j.psychres.2006.01.014.

Thomas, N., Hayward, M., Peters, E., van der Gaag, M., Bentall, R.P., Jenner, J., Strauss, C., Sommer, I.E., Johns, L.C., Varese, F., García-Montes, J.M., Waters, F., Dodgson, G., McCarthy-Jones, S., 2014. Psychological therapies for auditory hallucinations (voices): current status and key directions for future research. Schizophr. Bull. 40 (Suppl 4), S202-12. http://dx.doi.org/10.1093/schbul/sbu037.

Tsakanikos, E., 2006. Perceptual biases and positive schizotypy: the role of perceptual load. Personal. Individ. Differ. 41, 951-958. http://dx.doi.org/10.1016/ j.paid.2006.04.004

Tsoi, D.T., Lee, K., Khokhar, W.A., Mir, N.U., Swalli, J.S., Gee, G.P., Pluck, G., Woodruff, P.W., 2008. Is facial emotion recognition impairment in schizophrenia identical for different emotions? A signal detection analysis. Schizophr. Res. 99 (1-3), 263-269. http://dx.doi.org/10.1016/j.schres.2007.11.006.

Underwood, R., Kumari, V., Peters, E., 2016. Cognitive and neural models of threa appraisal in psychosis: a theoretical integration. Psychiatry Res. 239, 131-138. http://dx.doi.org/10.1016/j.psychres.2016.03.016.

Ungar, L., Nestor, P.G., Niznikiewicz, M.A., Wible, C.G., Kubicki, M., 2010. Color Stroop and negative priming in schizophrenia: an fMRI study. Psychiatry Res. Neuroimaging 181 (1), 24-29. http://dx.doi.org/10.1016/ j.pscychresns.2009.07.005.

Wiens, S., Syrjänen, E., 2013. Directed attention reduces processing of emotional distracters irrespective of valence and arousal level. Biol. Psychol. 94 (1), 44-54. http://dx.doi.org/10.1016/j.biopsycho.2013.05.001.

Wykes, T., Spaulding, W.D., 2011. Thinking about the future cognitive remediation therapy - what works and could we do better? Schizophr. Bull. 37 (Suppl 2), S80-S90 . http://dx.doi.org/10.1093/schbul/sbr064. 